\title{
STUDY OF FOOD WASTE AT SCHOOLS IN VIDZEME REGION
}

\author{
Rita Riekstina-Dolge $^{1 *}$, Ilze Beitane ${ }^{1}$, Sandra Iriste $^{1}$, Sabine Melbarde $^{2}$ \\ ${ }^{1}$ Department of Nutrition, Faculty of Food Technology, Latvia University of Life Sciences and Technologies, \\ Rigas iela 22, Jelgava, Latvia, e-mail: rita.riekstina@llu \\ ${ }^{2}$ Faculty of Veterinary Medicine, K. Helmana iela 8, Jelgava, Latvia
}

\begin{abstract}
The amount of food waste at schools is a topical issue because it shows the effectiveness of school catering system, dietary quality, pupils' attitudes and satisfaction with the offered food. The objective of this study was to determine the types of food waste, their amounts at schools in Vidzeme region and to analyse the pupils' attitude towards school meals. The study was carried out at five schools in Vidzeme region, making one-week waste food weighing. The survey method was used to determine pupils' satisfaction with school meals. Three kinds of food waste can be distinguished in school canteens, depending on where they are generated: food waste in preparation process, in distribution process and food waste from the left food portion, which accounted for $41 \%, 20 \%$ and $39 \%$ respectively. The amount of food waste in preparation process, which is influenced by seasonality, quality of food products, staff experience and working conditions, can be reduced by rational organization of the production process. The amount of food waste from the left food portion was influenced by the individual wishes of the pupils, family eating habits, the quality of food, the atmosphere in the school canteen, the way of serving lunch and the participation of teachers. Whereas a large amount of waste is due to the fact that children prefer novel foods rather than traditional ones, the possible solutions could be: adapting meals to pupils' habits, changing the way of serving, motivating and educating pupils and their parents.
\end{abstract}

Keywords: food waste, school's catering, pupils

\section{Introduction}

At the beginning of 2018, totally 2312 closed-type catering companies were registered in the Latvian FVS (Food and Veterinary Service) Register of Enterprises. $37 \%$ or 847 of closed-type catering enterprises work at primary and general education establishments.

Nowadays scientists' interest is focusing on school catering issues, because it affects a number of important problems that need to be solved (Falasconi, et al., 2015; Logario et al., 2018). Firstly, the large amount of food waste at the school canteens, which is due to (Balzaretti et al., 2018; Derqui, Fernandez, 2017; Rickinson et al., 2016):

1) pupils' eating habits (for example, some people eat such food, others - do not, for example bread crusts);

2) type of food / drink preparation (for example potato skins);

3) cooking process (for example meat bones, egg shells);

4) wrongly calculated the required amount of food (non-served food) and portion size (plate waste);

5) wrongly organized lunch refusals;

6) incorrectly planned length of breaks;

7) inappropriate canteen atmosphere, exterior appearance, furnishings and microclimate.

Secondly, alongside with the increase in food waste, the risk of malnutrition among pupils increases. Thirdly, the food waste at school canteens leads to the loss of environmental, work and financial resources. Furthermore, several studies in the food service industry have highlighted diverse food waste mitigation strategies e.g. different National School Lunch or Breakfast Programs.

Thus the objective of this study was to determine the types of food waste, their amounts at schools in Vidzeme region and to analyse the pupils' attitude towards school meals.

\section{Materials and Methods}

Five comprehensive schools in Vidzeme region were selected as the object of the research. The number of children served at the school canteen ranged from 115 to 684 children per day on average. To determine the amount of food waste at the schools, it was weighed for a week. The observation method was used to evaluate the pupils' eating process and lunch organization, analysed portions of food waste, which were divided into three categories:

1) production waste, which includes food/drink preparation and cooking process waste;

2) non-served food including improper planning or unscheduled refusal of lunch;

3) plate waste, that mostly arises from pupil's eating habits and inappropriate portion size.

Results of non-served food and plate waste quantities are expressed both in terms of weight and as percentage of the initial prepared food (Cohen et al., 2013). To compare the data, non-served food and plate waste was expressed per portion (pupil).

In order to understand the pupils' eating habits and the reasons for uneaten portions, an indirect survey was conducted in the study. 250 questionnaires were distributed at schools (50 at each school). 196 questionnaires (78.4\%) were returned and valid for the study. 196 respondents, aged 11-17, participated in the survey -115 girls and 81 boys. A semi-structured interview was used in the study - in which five school canteen managers were interviewed with the aim to obtain information on food waste problems at school catering and the factors affecting them.

The overall structure of the study is depicted in Figure 1. 


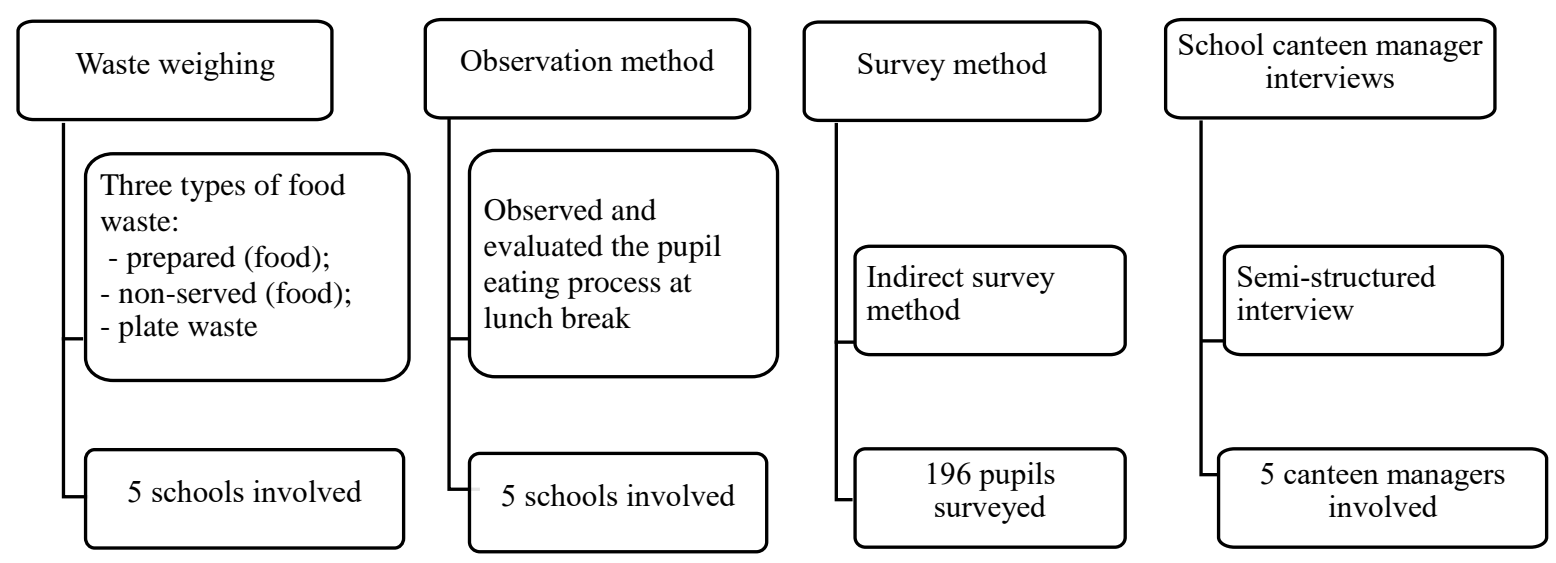

Figure 1. The structure of the research

Mathematical processing of data was performed with mathematical statistical methods using software MS Excel. The hypothesis was tested with p-value method and factors were considered to be significant, if p-value $<\alpha_{0.05}$ and $<_{0.001}$. For the result interpretation it was accepted that $\alpha$ is $0.05 \quad(\alpha=0.05)$ with $95 \%$ credibility if not stated otherwise. To analyse association of different parameters regression and correlation analysis were used. If the correlation coefficient value is $0.5 \leq|\mathrm{r}| \leq 0.8$, there is moderate linear correlation between researched parameters.

\section{Results and Discussion}

The results of the study showed that total food waste was $1112.5 \mathrm{~kg}$ in one week, most of which (41\%) was production waste. Production waste at schools ranged from $1.6 \%$ to $20.8 \%$ of the total amount of food prepared. Production waste consists of waste generated during the pre-treatment of products (vegetables, fruit peel, cores, egg shells), as well as during improper food storage. Production waste differed significantly between schools $(\mathrm{p}<0.001)$.

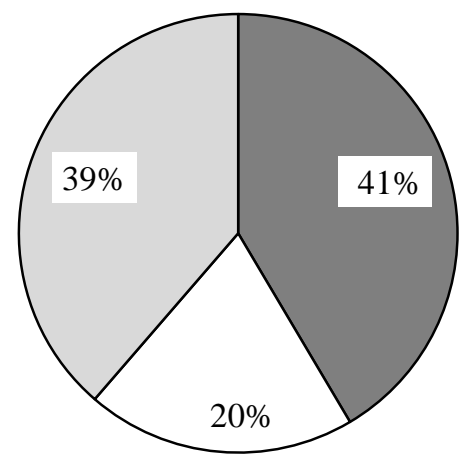

$\square$ Prepared (food) waste $\square$ Non-served (food) $\square$ Plate waste

\section{Figure 2. Total amount of waste}

Production waste is inevitable, but the quantity can be reduced by training employees using proper pretreatment of products, using high-quality equipment and by following up the correct food circulation (Fifo Principle) (Fink et al., 2016). Meanwhile, nonserved food and plate waste comprised $221 \mathrm{~kg}(20 \%)$ and $430 \mathrm{~kg}(39 \%)$ respectively. In a similar study on food waste in Italian schools, it was concluded that nonserved food and plate waste accounted for respectively $19.2 \%$ and $22.0 \%$ of prepared food (Boschini et al., 2018).

Non-served food and plate waste is waste, that is preventable and prevention is important for school catering. Research data showed that the amount of non-served food and plate waste was significantly different $(p<0.001)$ between schools. Non-served food waste ranged from an average of $1.7 \%$ to $12 \%$ of the total amount of food prepared (Fig. 3).

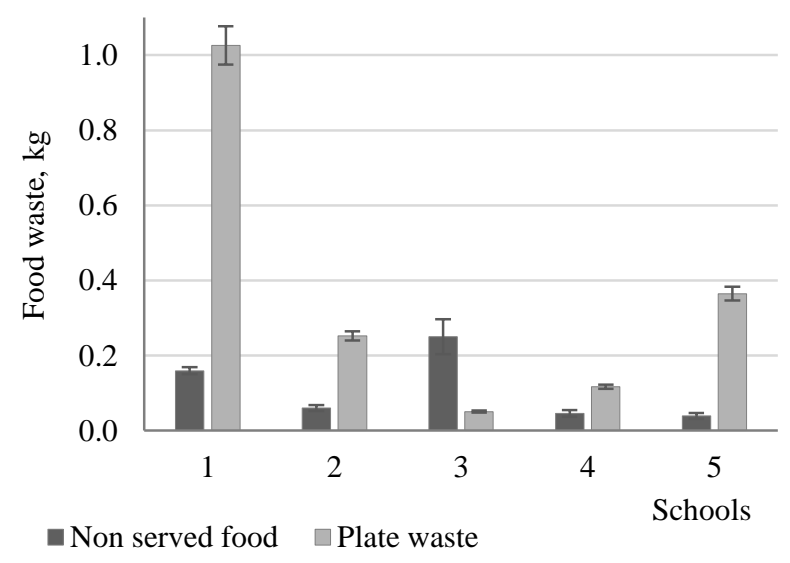

Figure 3. Non-served food and plate waste in schools by one pupil during one week

The large amount of cooked but non-served food might be due to improper planning or unscheduled refusal of lunch at school. This is one of the problems, especially if lunch is paid by the municipality and parents are not responsible for the timely refusal of lunch.

The amount of plate waste in school canteens ranged from $2.4 \%$ to $32.3 \%$ of the total amount of prepared meals. On average, one child produced between $0.05 \mathrm{~kg}$ and $1.03 \mathrm{~kg}$ of plate waste in one week, or even two portions per week. Schools 1 and 5 had the highest amount of plate waste, besides different types of serving. At school 1, pupils were offered ready-made portions that are not eaten by younger pupils. In the 
school 5, however, pupils themselves served food. In this case, it is necessary to explain to the pupils that the portions should be placed according to their appetite, and to encourage if the portion should be supplemented. The teachers and canteen staff should undertake the explanatory functions. One way to reduce plate waste would be pupils' self-service, when children put food on their own plates with the help of teachers. This would impose the food quantity that the pupil can eat as well as, that the child takes the necessary dietary norms.

A balanced and healthy meal is important for children in the growth process to provide the necessary energy reserves, which in turn is essential in the learning process. School meal programs provide opportunities for improvement of the nutritional quality of the diet, either in total energy, compensating for suboptimal foods consumed outside of school meals (Bartfeld, Ahn, 2011). Schools should especially think and look for solutions to reduce the plate waste, as children should receive a full-fledged meal that ensures the full intake of proper nutrients according to norms.

In order to justify the factors influencing the generation of waste in schools, correlation between the characteristics was used. The study analysed whether there was a correlation between the number of prepared meals and the amount of waste. The results showed an average close correlation ( $r=0.74)$, which could be explained by production process organization, cook work, raw material quality and inventory used. An average close correlation $(r=0.70)$ was observed between the prepared amount of food and the production waste, which meant that large amounts of production waste were not produced during the cooking process. When evaluating the correlation between the number of children and the plate waste, a weak correlation $(r=0.06)$ was observed, because a large number of pupils are not associated with large plate waste (Figure 4).

It is influenced by the age of the pupils, the size of the portions, the pupil's eating preferences, eating habits, food quality, etc.

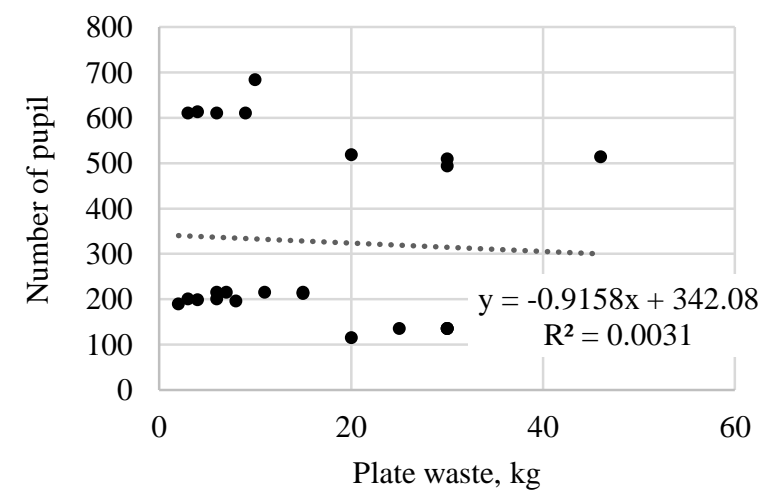

Figure 4. Correlation between number of pupils and plate waste weight

Observations on the pupils' eating process showed that the lunch takes place in a great noise and in a hurry that hinders the schoolchildren from enjoying the food.
Hurry was one of the reasons why pupils left the dish on the plate.

The atmosphere in the school canteen has an effect on children's eating habits, such as overcrowded dining halls and truncated eating time has been found to create time pressure on children (Moore et al., 2010), as well as hasty eating adversely affect the meals intake (Cohen et al., 2016).

Teachers' attitudes played an important role, the less teachers paid attention to those pupils, who were eating, the higher the number of uneaten portions. In schools where the eating process took place in a relatively calm atmosphere, the teachers actively participated in the lunch process, helped the children to lay portions and put in order the lunch table, the children had good eating habits. The pupils slowly ate their portions, left the table with the teacher that provided small amount of plate waste. Research data suggest that the choice of pupils for fruit or juice can be increased by up to $90 \%$ by involving school staff in encouraging schoolchildren to choose healthier products (Schwartz, 2007)

The results of the pupil survey showed that $48 \%$ of all pupils did not eat their school meal two or three times a week, which could be explained by large portions or unsavoury food. $37 \%$ of pupils would like to change the menu, making it more diverse so that the dishes are not repeated. The great part of the boys had emphasized the need to include more meat dishes in the menu. Asking the pupils about their favourite dishes, they called pasta, buckwheat, beetroot salad, fresh salad and fried potatoes. Whereas dishes that did not taste were named: soups, boiled potatoes, walnuts, porridge, and purees. The pupils indicated that they did not want so many and often potatoes, which can be explained by the Cabinet Regulation 172, which requires $450 \mathrm{~g}$ of potatoes to be included in the menu every week (Cabinet Regulations..., 2012).

Survey data showed that $82 \%$ of pupils did not think about food waste at school. In turn, $41 \%$ of respondents believe that they produce less than $0.5 \mathrm{~kg}$ of plate waste, but $12 \%$ of respondents $-3 \mathrm{~kg}$ or even more per week. These $12 \%$ include those pupils who pointed out they did not eat the whole portion at least three to four times a week. $86 \%$ of pupils also indicated that it would be necessary to reduce food waste in schools.

It shows the pupils' readiness to engage in the waste reduction process.

School canteen managers' interviews confirmed the conclusions of other studies on factors influencing pupils' eating habits.

One of the key factors highlighted is the change in pupils' eating habits namely dishes, which were popular several years ago, remaining uneaten nowadays. For example, if porridge with berry jam is offered, the children only eat the porridge, leaving the jam on the plate completely.

Canteen managers agreed on the inclusion of different types of soups in the menus: pupils eat unwillingly sour and fresh cabbage soup, as well as beetroot soup. Meatball soup and solyanka are eaten eagerly, possibly 
parents make these kinds of soups at home. Children refuse to eat different types of desserts, such as bread jelly, whipped cream, berry jelly as well as mousse. Pupils often do not eat puree and porridge, as well as salads. As garnish, children prefer pasta, buckwheat, rice instead of potatoes.

It was emphasized that children have begun to eat healthier, choose more cereals, steamed vegetables, steamed meat. In general, after the observations it was concluded that the amount of food waste from the left food portion was influenced by the individual wishes of the pupils, family eating habits, the quality of food, the atmosphere in the school canteen, the way of serving lunch and the participation of teachers. All these factors interact and influence the child's eating habits at school. Summarizing the results of the study, the authors created a model of factors that influence children's eating habits (Fig. 5).

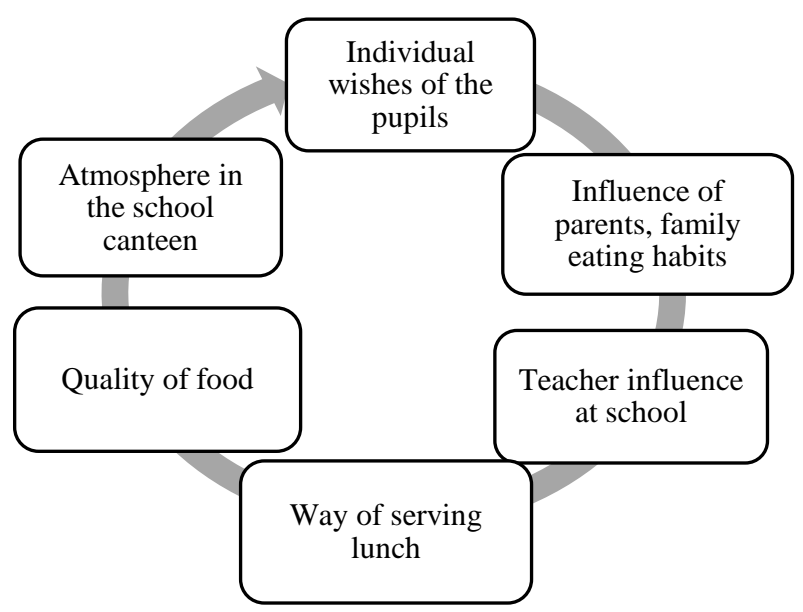

Figure 5. Factors affecting pupils' eating habits

Table 1

Food waste generating factors and recommendations for their reduction

\begin{tabular}{|c|c|c|}
\hline Type of food waste & Influencing Factors & Suggestions for reduction \\
\hline Production waste & $\begin{array}{l}\text { - low quality raw materials; } \\
\text { - seasonality; } \\
\text { - employee experience, knowledge and } \\
\text { professionalism; } \\
\text { - insufficient time available for the cooking } \\
\text { process; } \\
\text { - unmotivated employees }\end{array}$ & $\begin{array}{l}\text { - to educate employees; } \\
\text { - to buy quality raw materials; } \\
\text { - to plan work process and time; } \\
\text { - to motivate employees to work responsibly }\end{array}$ \\
\hline Non-served food & $\begin{array}{l}\text { - no possibility to refuse lunch; } \\
\text { - too much prepared food }\end{array}$ & $\begin{array}{l}\text { - to implement successive procedures for } \\
\text { refusing lunch; } \\
\text { - to plan precisely required amount of food }\end{array}$ \\
\hline Plate waste & $\begin{array}{l}\text { - tasteless, poor quality food; } \\
\text { - cool food; } \\
\text { - inappropriate portion size; } \\
\text { - modern eating habits; } \\
\text { - individual preferences of pupils; } \\
\text { - age of children; } \\
\text { - food presentation }\end{array}$ & $\begin{array}{l}\text { - to serve a delicious, high quality, good- } \\
\text { looking, appropriate temperature meal; } \\
\text { - to educate children; } \\
\text { - to involve teachers in the eating process of } \\
\text { lunch; } \\
\text { - to inform parents about such a problem and } \\
\text { involve them in solving it; } \\
\text { - let children to choose what to eat. }\end{array}$ \\
\hline
\end{tabular}

Successfully acting at all stages, it is possible to reduce food waste in school canteens: evaluate the stages of the production process, implement rational improvements to reduce food waste in the school, educate and motivate staff to carry out their duties qualitatively and responsibly, evaluate the food service organization. Regular plate waste analysis is required to observe pupils' eating habits and evaluate possible improvements (Table 1).

Teachers should take part in forming children's eating habits: explain the healthy and varied food intake beneficial effect on the body, educate on food waste reduction and its impact on the environment, be a healthy role model.

Responsible action can significantly reduce waste, but it requires motivation, desire and also awareness of the benefits.

\section{Conclusions}

The issue of reducing food waste is topical, new solutions for optimizing the production process and educating the society about sustainable lifestyle are being sought. The results of the study showed that it is possible to reduce both non-served and plate waste. There are two possible solutions:

1) more detailed research on lunch organization and production factors in schools, developing good practice examples;

2) improvement of pupils' nutrition regulation, promotion of healthy eating habits of pupils and improvement of lunch environment.

Properly organized lunch planning, which includes a sequential process of refusing lunch, can significantly reduce food waste from non-served food. The amount of plate waste is significantly different at all schools, mainly due to individual wishes of the pupils, family eating habits, the quality of food, the atmosphere in the school canteen, the way of serving lunch and the participation of teachers. Food waste reducing in school canteens is a complex issue that can be solved by involving canteen staff, school staff, and educating and motivating pupils and their parents. 


\section{References}

1. Balzaretti C., Ventura V., Ratti S., Ferrazzi G., Spallina A., Carruba M., Castrica M. (2018) Improving the overall sustainability of the school meal chain: the role of portion sizes. Eating and Weight Disorders - Studies on Anorexia, Bulimia and Obesity, p. 1-10.

2. Bartfeld J. S., Ahn H. M. (2011) The school breakfast program strengthens household food security among low-income households with elementary school children. Journal of Nutrition, Vol. 141, p. 470-475.

3. Boschini M., Falasconi L., Giordano C., Alboni F. (2018) Food waste in school canteens: A reference methodology for large-scale studies. Journal of Cleaner Production, Vol. 182, p. 1024-1032.

4. Cabinet regulation Nr.172 "Regulations Regarding Nutritional Norms for Educates of Educational Institutions, Clients of Social Care and Social Rehabilitation Institutions and Patients of Medical Treatment Institutions" (2012), Cabinet of Ministers. [accessed on 08.02.2019.]. Available: https://likumi.lv/doc.php?id=245300.

5. Cohen J., Richardson S., Austin S., Economos C., Rimm E. (2013) School lunch waste among middle school students: nutrients consumed and costs. American Journal of Preventive Medicine, Vol. 44, p. 114-121.

6. Cohen J. F., Jahn J. L., Richardson S., Cluggish S. A., Parker E., Rimm E. B. (2016) Amount of time to eat lunch is associated with children's selection and consumption of school meal entree, fruits, vegetables and milk. Journal of the Academy of Nutrition and Dietetics, Vol. 116, p. $123-128$.
7. Derqui B., Fernandez V. (2017) The opportunity of tracking food waste in school canteens: Guidelines for self-assessment. Waste Management, Vol. 69, p. 431-444.

8. Falasconi L., Politato A., Politano A., Segrè A. (2015) Food waste in school catering: An Italian case study, Sustainability, Vol. 7, p. 1-16.

9. Cohen J.F., Richardson S., Austin S.B., Bryn A., Economos C.D., Rimm E.B. (2013) School lunch waste among middle school students: nutrients consumed and costs. American Journal of Preventive Medicine, Vol. 44, p. $114-121$

10. Fink L., Roehl R., Strassner C., Antony F., Gensch C. O. (2016) Prevention of food waste in the catering sector, guideline, German Environment Agency, 36 p. [accessed on 24.01.2019]. Available: https://www.umwelt bundesamt.de/publikationen/prevention-of-food-wastein-the-catering-sector.

11. Logario A., Pinto R., Golini R. (2018) Food waste reduction in school canteens: Evidence from Italian case. Journal of Cleaner Production, Vol. 199, p. 77-84.

12. Moore S. N., Murphy S., Tapper K. and Moore L. (2010) The social, physical and temporal characteristics of primary school dining halls and their implications for children's eating behaviours. Health Education Journal, Vol. 110, p. 399-411.

13. Rickinson M., Hall M., Reid A. (2016) Sustainable school programmes: what influence on schools and how do we know? Environmental Education Research, Vol. 22, p. $360-389$

14. Schwartz M. B. (2007) The influence of a verbal prompt on school lunch fruit consumption: A pilot study. International Journal of Behavioural Nutrition and Physical Activity, Vol. 4, p. 6. 